Portland State University

PDXScholar

$5-25-2018$

\title{
Film Marketing on Instagram: A Model for Effectively Employing Influencers
}

Bryce Earhart

Portland State University

Follow this and additional works at: https://pdxscholar.library.pdx.edu/honorstheses

\section{Let us know how access to this document benefits you.}

\section{Recommended Citation}

Earhart, Bryce, "Film Marketing on Instagram: A Model for Effectively Employing Influencers" (2018). University Honors Theses. Paper 554.

https://doi.org/10.15760/honors.560

This Thesis is brought to you for free and open access. It has been accepted for inclusion in University Honors Theses by an authorized administrator of PDXScholar. Please contact us if we can make this document more accessible: pdxscholar@pdx.edu. 
Film marketing on Instagram: A model for effectively employing influencers

\author{
by \\ Bryce Earhart
}

\begin{abstract}
An undergraduate honors thesis submitted in partial fulfillment of the requirements for the degree of

Bachelor of Science

in

University Honors

and

Communication Studies
\end{abstract}

Thesis Adviser

Erin Spottswood, Ph.D.

Portland State University 


\section{TABLE OF CONTENTS}

$\begin{array}{lc}\text { Abstract } & 2 \\ \text { Introduction } & 2 \\ \text { Instagram } & 3 \\ \text { Instagram Influencer Marketing } & 5 \\ \text { Diffusion of Innovations } & 6 \\ \text { Opinion Leaders } & 7 \\ \text { Social System } & 10 \\ \text { Message } & 12 \\ \text { Case Study: Jurassic World \& Zach King } & 15 \\ \text { Conclusion } & 17 \\ \text { References } & 18\end{array}$ 


\begin{abstract}
This article discusses the diffusion process of Instagram influencer marketing for a film as sponsored content moves from an influencer through Instagram’s social network. Instagram influencer marketing is broken down into to three major pieces: the influencer, the social system, and the message. Each piece is explored within the context of Rogers' theory of Diffusion of Innovations to build a model that explains successful campaigns. This model is laid onto a case study of Universal Studios’ 2017 Jurassic World: Fallen Kingdom campaign to showcase an Instagram influencer effort employed by a major film studio. Identifying the diffusion that occurs during Instagram influencer marketing informs a film marketer's approach to effectively employing Instagram influencers.
\end{abstract}

\title{
Introduction
}

Today’s film marketer is faced with both an opportunity and a challenge when considering Instagram as a platform to market films. Instagram influencer marketing is on the rise as giant blockbusters such as Jurassic World and Zootopia successfully market with Instagram influencers, but a lack of existing research can leave a marketer with due hesitation. (Djafarova \& Rushworth 2017; zachking, 2018). Instagram influencer marketing is on the rise (Biaudet, 2017; De Veirman et. al. 2017; Djafarova \& Rushworth 2017). As of 2013, “65\% of companies are participating in influencer-based marketing (Technorati, 2013)” (Biaudet, 2017, p.6). Instagram is a photo sharing site on which hundreds of millions of users interact on a day to day basis (Chaykowski, 2018). Instagram influencers are "sophisticated media consumers whose reach is coveted by not only media companies but also brands (Swant, 2015)" because of their ability to sway consumer decisions (Dunkley, 2017, p.32). Marketing with Instagram influencers 
is found to be an effective tool in swaying consumer opinions and brand attitudes, which can ultimately drive sales (De Veirman et. al, 2017). As interest builds for Instagram influencer marketing, a need evolves for its analysis. This article provides the marketer with an effective path to measuring, predicting, and explaining the results of an Instagram influencer campaign for film.

\section{Instagram}

Instagram debuted on July 16, 2010 with a single picture posted by founder Mark Krieger (Bruner, 2016). The photo sharing app is now owned by Facebook, and has since grown to host 500 million users, including $63 \%$ of all millennials in the United States, and to be worth as much as $\$ 50$ billion (Chaykowski, 2018). Instagram is an app that enables users to engage collectively in conversation through the sharing of images and videos (Instagram Inc., 2018). Instagram’s founder, Krieger, believes that the platform transcends language, pointing to images as the "most powerful way of communicating” (as cited in Chayowski, 2018). The platform of Instagram is one of "food pics, animal photos, artsy images, and of course plenty of documentation of carousing” (Bruner, 2016). With users that communicate publicly online on a day to day basis, a marketer can use Instagram to reach a large base of potential consumers. There are three pieces that make up Instagram's social system: communication between users, how information is found, and communities behind accounts.

Communication between users happens primarily through posts: which are comprised of an image or video with an optional caption (Bruner, 2016). Users interact with posts through 'likes’ and comments, which are both metrics of a community’s engagement with the post. 'Likes' act as approval and acknowledgement that a user has seen the post while comments allow users to respond to the post with dialogue (Instagram Inc., 2018). Each post displays a 
metric of the 'likes' and comments that it has received including a list of the accounts that interacted with the post (Instagram Inc., 2018). Posts can also include hashtags, location tags, account tags which aid other users in finding the post.

Users find information on Instagram on their feed as well as through a search bar for hashtags, location tags, and accounts (Instagram Inc., 2018). A user's feed is made up of recent posts from the accounts that a user is 'following' (Instagram Inc., 2018). A user can curate their feed through selecting the specific accounts that they wish to 'follow'. If a user wants to find posts from accounts that they are not 'following,' they can search for a topic of interest in either the hashtag, location tag, or account search bar (Instagram Inc., 2018). Hashtags are words or phrases embedded into posts that function as searchable links, and location tags are searchable links relating solely to the location in which the post was reportedly taken. Accounts are the galleries of posts created by a specific user. Accounts are linked to a user's username and can be searched for by username in the account search bar. Through these search bars, a user is exposed to new accounts whose content they may wish to subscribe to.

Communities on Instagram are made up of groups of users that 'follow' a specific account. Communities are formed when multiple users 'follow' the same account. Each 'follower' finds the account through their own search of Instagram’s information (Instagram Inc., 2018). Mutual interest in the account leads a group of users to interact with each other as the users engage with the account through 'likes' and comments (Instagram Inc., 2018). Accounts on Instagram can be held by users that are individuals, public figures, and brands (Instagram Inc., 2018). Whether an account is backed by a corporation or an individual, communities on Instagram form around it for the same reason; mutual interest. Instagram’s social system, 
however, can only blur the line between individuals and public figures, both showcasing glimpses into personal life. This cannot be said for brands.

\section{Instagram Influencer Marketing}

Instagram influencers are not brands, they are real people. Influence describes the process of affecting a consumer's behavior without directly giving commands (Almgren, 2018). On Instagram, influence is shifting away from traditional celebrities such as actors, filmmakers, and public figures towards the accounts of key 'Instafamous’ personalities such as bloggers, Youtubers, and non-traditional celebrities (Djafarova \& Rushworth, 2017). The more industry savvy term is 'Instagram Influencers,' which De Veirman et. al use as a label for Instagram accounts with an elevated level of influence on peers (2017). Given Instagram’s social system, an Instagram influencer is the account of a person, not a brand or celebrity, that holds a large community of 'followers'. Significant to a marketer, Instagram influencers feel more accessible to a typical Instagram user than a celebrity or brand does, affording them "higher authenticity and credibility, which subsequently leads to lower resistance to the message” (De Veirman et. al. 2017, p.798). An Instagram influencer is perceived to be a friend with high social capital, and therefore is easier for users to trust. Instagram influencer's also come tailor-made with their own unique community of users surrounding them due to the way that communities form on Instagram.

Instagram Influencer marketing generates online communication, or 'buzz,' about a specific product or brand (Biaudet, 2017). The communications of past, present, and potential consumers in relation to a product or brand online is referred to as electronic word of mouth (eWOM) (De Veirman et. al., 2017, p.801). On Instagram, eWOM takes place over the 'likes', comments, and posts that make up the platform's available communication tools. The results of 
an Instagram influencer campaign can best be measured through “cost-per-engagement (CPE)... in terms of dollars spent per 'like’ [or] comment” (Biaudet, 2017, p.29). CPE focuses on the measurable values of brand awareness and attitudes made apparent through eWOM. CPE takes advantage of the publicly viewable data of platforms such as Instagram to provide quantifiable results for influencer campaigns.

\section{Diffusion of Innovations}

Everett Rogers’ theory of Diffusion of Innovations (DOI) tracks an innovation, or new idea, as it is communicated and adopted within a social system over time (1962). Rogers' theory has been cited in over 55,000 scholarly journal articles, lending it credibility as a predictive model for information diffusion (Geary 2017). A marketer can use DOI to explain the outcome of an Instagram influencer campaign due to DOI’s ability to track the movement of information through a social system (Rogers, 1962). Most significantly, DOI provides key insight to the path of least resistance for information as it spreads by word of mouth from an influential member of a social system.

Roger’s DOI is composed of four main moving parts. These are “(1) the innovation, (2) it's communication from one individual to another (3) in a social system (4) over time” (Rogers, 1962, p.12). Rogers defines an innovation as information that is newly presented to a community (1962). An innovation can be spread through social channels by diffusion, which is defined as an idea’s movement from one member of a community to the next by word of mouth (Rogers, 1962). A social system is defined by DOI as “a population of individuals who are functionally differentiated,” but that still engage in collective behavior (Rogers, 1962, p.14). The process of a new idea diffusing through a social system by word of mouth is measured by Rogers over the 
axis of time (Rogers, 1962). This process of communication creates a predictive model of information diffusion.

The diffusion of an innovation takes an 's curve' shape in which time is the $\mathrm{x}$ axis and the number of adopters is the y axis as an innovation moves towards saturation (Chumer, 2002). Adopters are defined by Rogers to be members of a social system who are presented with and then embrace an innovation (1962). An opinion leader is an adopter who is "influential in approving or disapproving new ideas” (Rogers, 1962, p.209). An innovation reaches saturation when it has been adopted by the largest number of people who are ultimately willing to adopt it (Rogers, 1962). DOI points to opinion leaders, social systems, and innovations as pieces of the diffusion process that can be manipulated to minimize the resistance of an innovation (Rogers, 1962). Lowering resistance to an innovation increases the likelihood of its faster and more widespread adoption (Rogers, 1962).

\section{Opinion Leaders}

Influencers are key members of an Instagram social group that affect the buying behavior of a large number of users through a heightened perception of credibility (Djafarova \& Rushworth, 2017). Rogers’ theory identifies members of a social group that hold a superior amount of influence on peers as opinion leaders (1962). Similar to Instagram influencers, opinion leaders are members of a social group “from whom others seek advice and information” (Rogers, 1962). Instagram influencers function as opinion leaders to their community of followers.

DOI outlines the traits that lend opinion leaders advantage over their peers, which a marketer can consider when selecting an effective influencer. Rogers posits that "opinion leaders differ from their followers in information sources, cosmopoliteness, social participation, social 
status, and innovativeness” (1962, p. 237). These traits can be weighed by a marketer to judge the effectiveness of a hired influencer as an opinion leader. The theory first identifies that opinion leaders are unique because they rely on information from "impersonal, technically accurate, and cosmopolite sources” as opposed to other members of the social system (Rogers, 1962, p.238). This might be identified through interviewing potential influencers about the media that they consume. Using Instagram's platform, a marketer can look to the users that an influencer is following and the posts of an influencer to identify these sources and interests (Instagram, Inc., 2018). For example, if an influencer is following The New York Times and has posted about the \#metoo movement by citing information from a newspaper or academic source, then they showcase a behavior of consuming news media. News sources are less likely to bias and misinterpret the presentation of an idea than word of mouth communication (Rogers, 1962).

The second trait identified by Rogers is cosmopoliteness, which is expressed through an opinion leader's behavior; such as attendance of formal organizations and through the types of social relationships held by an opinion leader (Rogers, 1962). A marketer can identify an influencer's cosmopolite friends through an examination of the number of followers held by users who both follow and are followed by the influencer (Instagram Inc., 2018). A marketer can easily identify if an influencer attends formal social functions through the content of their posts (Instagram Inc., 2018). For example, an influencer who attends sponsored events or is friends primarily with other influencers might be considered more cosmopolite than one who does not. DOI identifies social participation, the accessibility of an opinion leader to their followers, as a desired trait of an active influencer (Rogers, 1962). A marketer can examine the frequency that an influencer directly engages their audience in order to identify their social participation. For example, how often an influencer responds to comments, direct messages, and 
posts that they are tagged all show how an influencer interacts directly with their audience (Instagram Inc., 2018). An influencer who makes a habit of responding to and directly engaging their audience is therefore more useful to a marketer.

Rogers points directly to the social status of an opinion leader as aiding the impact of their influence (Rogers, 1962). This translates onto Instagram as the number of followers held by the influencer (Instagram Inc., 2018). The number of followers held by an influencer is the most commonly cited marketing reason for their success in engaging an Instagram audience (De Veirman et. al., 2017; Djafarova \& Rushworth, 2017). Along with number of followers, an influencer's follower ratio can be an indicator of their social status on the platform (Instagram Inc., 2018). Social status is an important indicator of an influencer's power but should not be the only trait that a marketer considers.

An influencer who exhibits innovativeness is more likely to act as an active opinion leader (Rogers, 1962). While opinion leaders are not necessarily early adopters within a community, they adopt innovations before their followers and are generally considered to be innovative members of a social system (Rogers, 1962). A marketer can examine this behavior in an influencer through their posting habits. If an influencer consistently posts about trending topics, new products, or new ideas before they become popular, they are an active and innovative member of their social group. An influencer would be considered more innovative if they were to post about fidget spinners, the film Get Out, and planking before they reached peak virality. Taking DOI into account, an influencer should hold the characteristics of unique information sources, cosmopoliteness, social participation, social status, and innovativeness for them to best market an innovation. The active opinion leadership of an influencer solidifies Rogers' predictive bell curve of adoption, ensuring the successful generation of eWOM at low CPE. In 
other words, an influencer who holds Rogers’ traits of opinion leadership is more likely to be successful for word of mouth marketing campaigns.

\section{Social System}

When planning a campaign, the marketer looks to the community of users behind the influencer as an ideal target audience. To be an ideal target audience, this community needs to accept the diffusion of information easily. The community of users behind the influencer can be tested against the idea of Roger's social system. To do so, the marketer should first account that Rogers identifies two ideal types of social systems: traditional and modern (1962). Modern social systems are more likely to allow for the easy adoption of new information (Rogers, 1962). For a target audience to be more readily diffusible, both its social system and individual members would ideally showcase what Rogers identifies to be ‘modern norms’ (1962). A marketer can create and examine a target audience for an influencer campaign using five ideal social system norms laid out by DOI; urban, science and education, cosmopolite, economically rational, and empathetic (Rogers, 1962).

First, if an influencer's set of followers is comprised of more users with urban values, the target audience is more likely to be easily diffusible. A marketer can search for hashtags in a user’s posts, phrases in a user’s captions, phrases in a user’s bio, content of a user’s images, locations tagged to posts, and locations referenced in captions that are coded for 'urban' (Instagram Inc., 2018). An urban audience member in Portland, Oregon might post photos of downtown Portland, or use hashtags such as \#rosecity or \#citylife. To test and find an urban social group on Instagram, a marketer can employ software or a representational content analysis of the sample. 
DOI identifies modern social groups and individuals as adhering to the social norm of placing “a high value on science and education” versus a more traditional devaluation of these values (Rogers, 1962, p.61). A target audience holding these values is more likely to be an easily diffusible channel for a marketer’s message. A marketer can identify these values through employing either software of representational content analysis of users’ communication valuing 'science' and 'education'. A user who holds these values may post about school, or Earth Day. They may follow the accounts of public figures such as Bill Nye.

The ability to empathize is another key piece of DOI’s modern ideal type (Rogers, 1962). The same tactics can be used to perform a representational content analysis, coding for 'empathy’. A marketer will have to consider that they are coding for empathetic behavior. This might express itself on Instagram as a user commenting on a post with a sympathetic phrase such as 'I'm sorry' or 'that's too bad'. It is difficult to truly test for empathy; however, it is possible to establish that a community showcases this trait.

The final two traits of Rogers' modern social system require a survey methodology for identification, which Rogers himself uses to analyze the ideal types of social groups (Rogers, 1962). Modern individuals and social groups are defined by DOI to allow "new ideas [to] enter the social system freely from external sources," with "members of the system interact[ing] often with outsiders,” (Rogers, 1962, p.61). A marketer can survey users about interactions with members outside of their community. An Instagram user exhibiting this behavior might be an active follower of a fashion influencer, but comment often on the feed of a separate fashion influencer. Another example would be a user that responds to comments on their posts from strangers. 
Finally, DOI identifies modern individuals and social groups as making decisions that are economically rational as opposed to emotional (Rogers, 1962). Members of a social system that exhibit logic are more likely to consider an innovation from a logical perspective as opposed to rejecting it for emotional reasons (Rogers, 1962). For users to be more likely to respond to a sponsored post about a film on Instagram, it would be helpful if they exhibited a similar logic. A survey would be the most appropriate method for exploring the economic rationality of a group of Instagram users. The ideal user might describe themselves not as an impulse buyer, but as someone who weighs the benefits of a product before purchase.

A marketer can use these five characteristics of easily diffusible social systems to further test if their identified target audience and niche is appropriate for their message. Ideally, the most modern social system would be chosen for diffusion of the marketer's message to be able to reach its greatest potential level of saturation (Rogers, 1962). Another consideration for a marketer in selecting the target audience is the number of active opinion leaders within the audience. Opinion leaders within a social system can be found by using the same methods that assess a successful influencer. A higher number of opinion leaders in an Instagram social system can be positively linked to the ease of the diffusion of the marketer's message (Rogers, 1962). These characteristics of a potential audience ultimately help a marketer keep CPE low by ensuring the easy spread of the message.

\section{Message}

A marketer can use DOI to examine the message to be communicated to consumers on Instagram to ensure its effectiveness. DOI provides five characteristics of an innovation that lead to its ease of adoptability: relative advantage, compatibility, complexity, divisibility, and communicability (Rogers, 1962). For an influencer’s post to hold the greatest likelihood of 
adoption, it should adhere to these five standards. Relative advantage describes the way that an innovation is "superior to ideas it supersedes" (Rogers, 1962, p.124). A marketer should consider the outstanding qualities that are exhibited by the film. If selling a zombie movie, a marketer may identify that the film is unique from recent zombie films because of its sense of humor and the time period in which it is set. By emphasizing these unique traits, the marketer can showcase the film's superiority to similar films that lack these qualities. The marketer can also simply pose zombie films as superior quality over non-zombie related films. It is important to know the benefit that an innovation provides a community over past innovations (Rogers, 1962). In the film industry, it makes sense that this concept would translate to the idea of providing superior entertainment.

Rogers identifies compatibility, or the "degree to which an innovation is consistent with existing values and past experiences of the adopters,” as a characteristic of a successful innovation (Rogers, 1962, p.126). A marketer should consider the values held by the target audience while constructing the message. The values held by an audience might be found in the hashtags, images, captions, and interactions of users (Instagram Inc., 2018). This can be explored similarly to the coding of social systems, using content analysis and survey of potential consumers. There are two ways a marketer can apply this to the message. First, a marketer can choose to target an audience that aligns with the values of the film. For example, a family movie would mesh more easily online with a community of mothers than with a community of skaters. Second, a marketer can use influencers to target audience members who might not typically see movies of the genre of film being marketed, so long as the message conveys values that align with the community. If a marketer can successfully frame a film as aligned with social system values, then influencer marketing can be used to attract entirely new audiences to a film. 
The third component of a successful message is complexity, with ideas perceived as simpler being more readily adopted (Rogers, 1962). A marketer can use this sentiment when creating the message to ensure that concise information is delivered to the target audience through the influencer. For example, an influencer posting a video with a lengthy review of a film may be less effective than an influencer who posts a photo of themselves on the red carpet. The same concept can be applied to any characteristics about the film being communicated. If a marketer is trying to reach a fashion influencer's followers for a superhero film, rather than stressing the vast universe that exists in the film the message should focus on key points of information that are compatible with fashion, like costuming.

The divisibility of a message is the degree to which availability of a free trial exists (Rogers, 1962). Unfortunately, there is not an option for a consumer to attend a trial period of a film viewing at a theater for free before committing in the same way that streaming services can offer a month free. However, the trailer of a film can function as a trial. The idea of an audience member being able to watch a two-minute edit that represents a film without having to put money down aligns itself with DOI. It may be more effective for the content of an influencer campaign to point the target audience toward a trailer than to simply inform them of the film.

Finally, Rogers points to communicability, or the ease of a message to be shared, as a characteristic of a successful innovation (Rogers, 1962). This principle puts the marketer using Instagram to generate eWOM at an advantage. Given that Instagram is an easily diffusible platform, a marketer can position the message with ease for it to perform well. To position a message to diffuse with as little resistance as possible, a marketer can consider all positive characteristics of an influencer, an audience, and a message outlined by Rogers' theory. These 
pieces work congruently for a marketer to construct an advantageous social system on Instagram with a fitting influencer and message.

Once a marketer breaks down the social system into Rogers’ characteristics, it should behave in accordance to Rogers’ predictive theory. Understanding the working pieces of an Instagram influencer campaign allow for its testability, and for a marketer to achieve the best possible resulting CPE from that campaign.

\section{Case Study: Jurassic World \& Zach King}

In early December of 2017, Instagram influencer Zach King released an exclusive sketch to promote the release of the trailer for Universal Studios’ Jurassic World: Fallen Kingdom (Instagram Inc., 2018). The Instagram post received upwards of 6.6 million views, 912,000 'likes', and 5,400 comments (zachking, 2018). The post features a video of the film’s stars, Chris Pratt and Bryce Dallas Howard, running through an office to upload the film's trailer with Zach while he performs video magic tricks (zachking, 2018). The post serves as an example of a major film company, Universal Studios, using Instagram influencer marketing. The campaign can be broken down to show successful integration of Rogers’ DOI.

With 21.8 million followers against 24 accounts followed, Zach King is easily identifiable as an influencer through his higher than average number of followers on Instagram (De Veirman et. al., 2017; zachking, 2018). He is known for creating video magic tricks in which he uses editing to surprise and entertain his audience (Smith et. al., 2015). Zach King is an internet personality, not an actor. Universal Studios partnership with Zach molds together the story and cast of Jurassic World with Zach’s brand of online magic (zachking, 2017). 
Along with being an Instagram influencer, Zach meets the qualities of an opinion leader. DOI identifies unique information sources, cosmopoliteness, social participation, social status, and innovativeness as key traits of opinion leadership (Rogers, 1962). Zach King's main account steers clear of politics and the news, however his account zachkinglife shows a photo of the influencer at the White House Correspondent’s Dinner with scientist Bill Nye and fellow influencer Cameron Dallas (2016). This post serves as insight to Zach's information sources and cosmopoliteness. His attendance of the largest event celebrating the free press in the U.S. can be tied to his consumption, or at least support, of hard news sources. Attendance of the event also points to Zach’s connections with celebrities and politicians. Zach King's main account showcases him as an influencer with an elevated level of social participation. The account contains many posts calling for engagement, such as “Anybody have a birthday soon?” and “submit a fun or magical selfie and use the \#MyMagicalSelfie so we can find it,” where followers can win a chance to be drawn as a character in his book (zachking, 2018). These calls to action show social engagement between Zach and his audience. Zach’s number of followers alone prove him to hold social status on the platform (zachking, 2018). Finally, Zach has a track record of innovation through previous sponsored messages such as ads about Zootopia, the Oscars, and new mobile phone releases (zachking, 2018). A marketer could easily analyze Zach King as an influencer who holds strong opinion leadership in Instagram’s social system. What's more, these qualities in Zach can be compared to other innovators to select characteristics compatible to a given campaign.

To identify Rogers’ ideal types for Zach’s audience, a marketer would have to perform survey and content analysis. While Zach's reach of 21.8 million followers is impressive alone, a marketer could work to ensure a more favorable CPE through audience analytics (zachking, 
2017). It is easy to see that the message delivered by Universal Studios through Zach's account matches well with Rogers’ qualities of successful innovations. DOI identifies a successful message as holding the characteristics of relative advantage, compatibility, complexity, divisibility, and communicability (Rogers, 1963). Instagram’s platform accounts for the communicability of the message, affording posts an easily diffusible network built of comments, 'likes', and hashtags (Instagram Inc., 2018). The message Universal puts forward is simple, calling Zach’s audience to watch a video about the movie. This in turn points to the divisibility of the innovation. The post makes it easy for users to try out the universe of Jurassic World before buying a ticket, offering free content that exists even outside of a trailer. Regarding compatibility and relative advantage, a marketer would first need to have an in-depth analysis performed of Zach’s audience and of similar films in order to proceed. The high-tech film appears to mesh well with Zach’s brand of special effects videos. Marketers should consider the use of Instagram influencers to market even the biggest of blockbuster films such as Jurassic World, and clearly Universal Studios finds a value in an influencer such as Zach King.

\section{Conclusion}

Applying Rogers’ model of Diffusion of Innovations to film marketing on Instagram builds a clear-cut path for marketers and researchers to further explore the strategy of Influencer marketing. The social system on Instagram fully satisfies Rogers’ intricate model. As eWOM campaigns continue to grow in number, application and testing of Diffusion of Innovations on Instagram are the next steps for film marketers seeking to increase box office results. The response to the Jurassic World \& Zach King campaign makes it clear that Influencer marketing works, but the research backing the methodology is non-existent. The largest limitation of this work is in its reliance on a theoretical application of Rogers' theory without scientific evidence. 
Additional research, testing the predictability of an Influencer's post early on in a campaign, would be necessary to prove Rogers’ theory as it applies to eWOM marketing. Once the statistical groupings of innovators, early majority, late majority, and laggards is established, coding could further break down traits of each group to be targeted by marketers. Furthermore, manipulating various traits of a message at each of the key points of Rogers' model would help test the success of various eWOM strategies, laying a broader groundwork of research to help marketers and social scientists understand the social system present on the platform. Diffusion of Innovations begins to unpack the potential of Influencer marketing, providing the theory behind potential quantification of Instagram marketing. It is one thing for a marketer to see large numbers of 'likes' and comments, and it is another thing to be able to manipulate a campaign to efficiently speak to a community. As the industry continues to move online and away from traditional mediums, applying theory to unchartered territory is a start to a deeper understanding of quantifiable campaign strategy.

\section{References}

Biaudet, S. (2017). Influencer marketing as a marketing tool the process of creating an influencer marketing campaign on Instagram. (Degree Thesis). Retrieved from Theseus.fi Academic Studies and Publications.

Bruner, R. (2016, July 16). A Brief History of Instagram's Fateful First Day. Time. Retrieved from http://time.com/4408374/instagram-anniversary/

Chaykowski, K. (2016, August 1). Instagram, the \$50 billion grand slam driving Facebook’s future: The Forbes cover story. Forbes. Retrieved from https:/www.forbes.com/sites/kathleenchaykowski/2016/08/01/instagram-the-50-billion grand-slam-driving-facebooks-future-the-forbes-cover-story/\#92b66144a972 
De Veirman, M., Cauberghe, V., \& Hudders, L. (2017). Marketing through Instagram Influencers: the impact of number of followers and product divergence on brand attitude. International Journal of Advertising, 36(5), 798-828. doi: 10.1080/02650487.2017. 1348035

Djafarova, E., Rushworth, C. (2017). Exploring the credibility of online celebrities’ Instagram profiles in influencing the purchase decisions of young female users. Computers in Human Behavior, 68, 1-7. doi: 10.1016/j.chb.2016.11.009

Geary, P. (2017). \#TheRightToRemainSilent: Police department adoption and deployment of social media, 2010-2015 (Master’s Dissertation). Retrieved from ProQuest Dissertations and Theses Global database. (Order No. AAI10147470).

Instagram (2018). Instagram, Inc. (Version 44.0) [mobile application software]. Retrieved from http://itunes.apple.com

Katona, Z., Zubcsek, P.P., \& Sarvary, M. (2011). Network effects and personal influences: The diffusion of an online social network. Journal of Marketing Research 48, 425-443.

Moss, E. (2014, June 11). I tried using Instagram like a teenager- and it completely changed the way I see the app. Business Insider. Retrieved from http://www.businessinsider.com/how-teens-use-instagram-2014-6

Rogers, E. (1962). Diffusion of innovations. New York: Free Press of Glencoe.

Rogers, E., \& Shoemaker, F. Floyd. (1971). Communication of innovations: A cross-cultural approach (Second ed.). New York: Free Press.

Simmons, L.L., Mukhopadhyay, S., Conlon, S., \& Yang, J. (2011). A computer aided content analysis of online reviews. Journal of Computer Information Systems 52(1), 43-55. 
Shalev, E., \& Morowits, V. G. (2012). Influencer via comparison-driven self-evaluation and restoration: The case of the low-status influencer. Journal of Consumer Research, 38(5), 964-980.

Smith, R., Crawford, S.K., \& Effron, L. (2015, March 5). How Vine genius Zach King pulls off eye-popping magic tricks in 6 seconds. $A B C$ News. Retrieved from https://abcnews.go.com/Lifestyle/vine-genius-zach-king-pulls-off-eye popping/story?id=29424652

Varol, O. (2017). Analyzing social big data to study online discourse and its manipulation (Order No. 10281756). Available from ProQuest Dissertations \& Theses Global. (1925045818).

zachking. (2017, December 5). I’m totally getting fired... [Instagram post]. Retrieved from https://www.instagram.com/p/BcUs5dZjLbL/?hl=en\&taken-by=zachking zachking. (2018). Stories can make people smile... [Instagram account]. Retrieved from https://www.instagram.com/zachking/?hl=en zachkinglife. (2016, April 30). White House correspondence dinner [Instagram post]. Retrieved from https://www.instagram.com/p/BE2WvkBLl7J/?hl=en\&taken-by=zachkinglife 